\title{
Air Ventilation and Thermal Comfort in a Tramcar
}

\author{
Ugur Demir ${ }^{1}$, Saeid R. Angeneh ${ }^{1}$, Durmus Sagir ${ }^{2}$, Murat K. Aktas ${ }^{1}$ \\ ${ }^{1}$ TOBB University of Economics and Technology \\ Sogutozu Cad. \# 43, Ankara, Turkey \\ ugurdemir@etu.edu.tr; sraheimpour@etu.edu.tr; maktas@etu.edu.tr \\ ${ }^{2}$ Bozankaya Inc. \\ Sincan 1.OSB Artuklular Sokak \# 3, Ankara, Turkey \\ durmussagir@bozankaya.com
}

\begin{abstract}
In the present study, heating, ventilation and air conditioning (HVAC) vents of a tramcar passenger cabin were designed by utilizing computational fluid dynamics (CFD) analysis. Three dimensional and transient numerical simulations were performed in order to obtain the flow and the temperature fields in the cabin. The time dependent Navier Stokes and energy equations for turbulent flow conditions were solved by a commercial CFD package (ANSYS Fluent). The obtained temperature distribution and the air circulation velocity in the cabin comply with the EN 14750-1 standard for both cooling and heating modes of the air conditioning unit. The proposed vent design provides an improved thermal comfort compared to the existing vent structure in the tramcar.
\end{abstract}

Keywords: Thermal comfort, Air Ventilation, Thermal management, CFD.

\section{Introduction}

As a solution to the traffic problems encountered in urban transportation, administrations encourage public transportation such as buses, trams, and subways instead of private vehicles. Transportation with high passenger capacity vehicles decreases the number of vehicles in the traffic. It also reduces the environmental pollution. Light rail systems (tram, metro, etc.) are preferred in public transportation due to their high capacity, safety, comfort conditions, long operating life and low cost. The metropolitan cities prefer the tram-trains if the geographic conditions allow since the infrastructure costs to be relatively lower compared to an underground subway system. It is a demand of city governments that the trams should be equipped with ventilation systems that maximize the passenger comfort, have high energy efficiency and environmental sensitivity and comply with international standards.

The air quality and the thermal comfort in various passenger vehicles were the subject of a number of studies in literature [1-4]. The thermal comfort in tramcars or railway systems received relatively less attention in the existing literature [5, 6].

The aim of this study is to design the air blowing vents (diffusers) of a tramcar ventilation system for the passenger cabinets. The developed vents will be the essential part of the HVAC system of the tramcar cabin and will be in accordance with the EN 14750-1 Railway applications - Air conditioning for urban and suburban rolling stock - Part 1: Comfort parameters standard. The fluid velocities specified at the head level in this standard are the most essential design constraints for the air vents of the cabin. The pre-heating (winter mode) and the pre-cooling (summer mode) times should be minimum before taking the tram to the service. The most important temporary change occurs when the tram opens the doors at the station during the passenger boarding. The ability to bring the cabin temperature conditions back to desired values in case of a temporary change is another important design criterion for the air conditioner unit and ventilation ducts.

\section{Problem Definition}

The size of the tramcar under investigation is approximately $32.7 \mathrm{~m} \times 2.6 \mathrm{~m} \times 2.4 \mathrm{~m}$. The tram consists of 5 wagons with a shorter central wagon. Two ventilation inlets which are placed at the middle region on the ceiling of the tramcar supply the conditioned air at the rate of $1.2 \mathrm{~kg} / \mathrm{s}$. The design parameters are considered based on EN 14750-1 standard. The standard sets an upper limit for the air velocity in the cabin for the standing and seated passengers: The desired air velocity is at most $0.3 \mathrm{~m} / \mathrm{s}$ at the head level. The cabin temperature should be $10{ }^{\circ} \mathrm{C}$ at $-40{ }^{\circ} \mathrm{C}$ outside temperature. The desired cabin temperature is $31{ }^{\circ} \mathrm{C}$ at $40{ }^{\circ} \mathrm{C}$ outdoor temperature. In addition, the ventilation system should provide ideal temperature in both heating 
and cooling modes before the start of daily operation. The tram is typically in motion for 2 minutes between the stations and stops for 20 seconds doors open for the passenger entry and exit.

The solid model of the tramcar with passengers is shown in Figure 1a. The capacity of the tram is 290 passengers. The passengers were approximated as rectangular prisms in the numerical model (Fig. 1b).
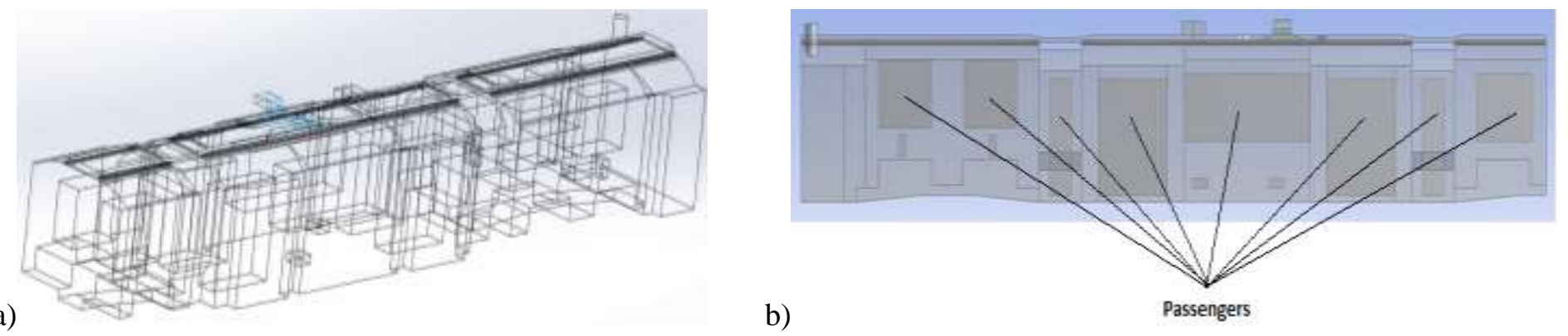

Fig. 1: a) The isometric view of the tram under investigation, b) Passengers in the tramcar (side view).

Fig. 2a depicts the geometry of the ventilation port and the proposed vent design with detailed dimensions. The ventilation duct is located at the ceiling of the tram and has nearly rectangular cross section $(76 \mathrm{~cm} \mathrm{x} 10 \mathrm{~cm})$.

a)

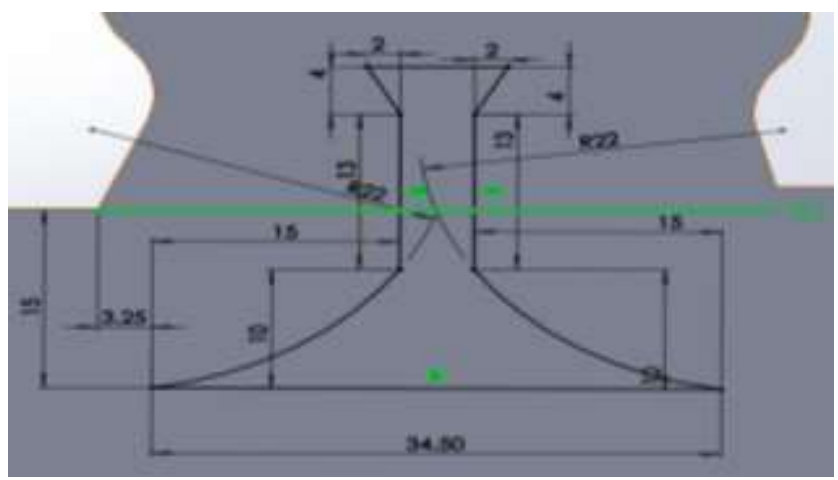

b)

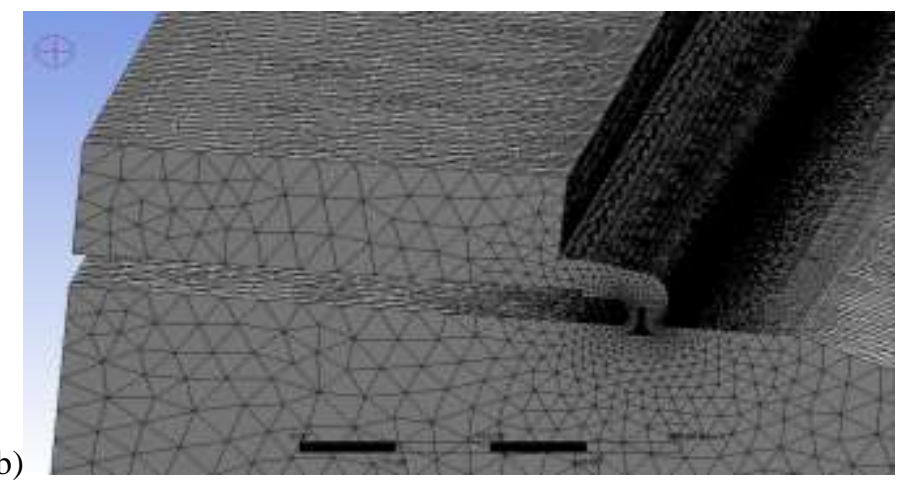

Fig. 2: a) The ventilation duct and the vent geometry (all units are in $\mathrm{mm}$ ), b) The numerical mesh structure.

The air velocity in the duct must not exceed $7 \mathrm{~m} / \mathrm{s}$ in order to satisfy noise level requirements. The ventilation port connects the duct and the air vents. The vent plate is located $15 \mathrm{~mm}$ below the ceiling. Air flows from this opening to the cabin.

\section{Numerical Method}

A commercial CFD package (ANSYS Fluent) was employed for the numerical simulations.

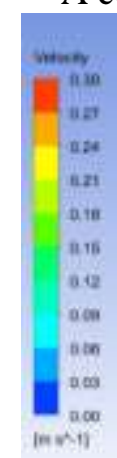

a)
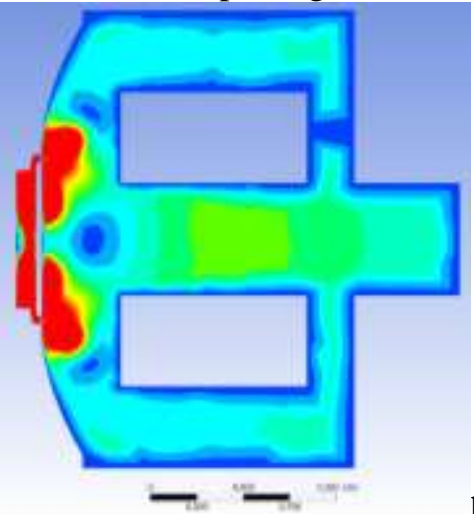

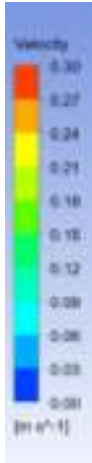

b)
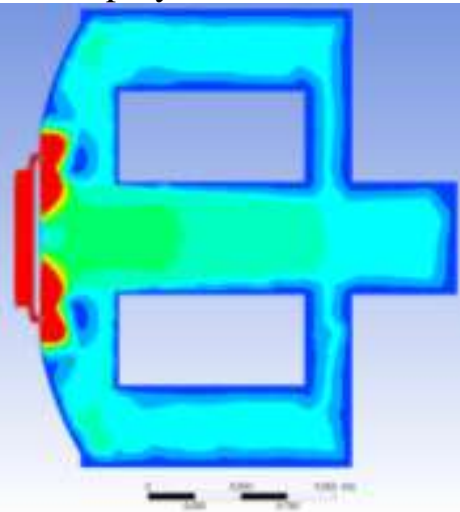

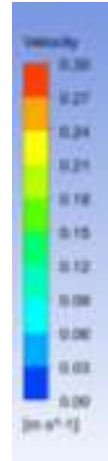

c)

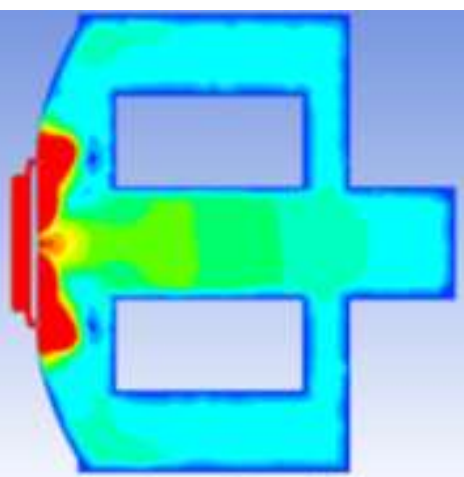

$-=$

Fig. 3: Velocity field with a) 10 million mesh, b) 20 million mesh, c) 40 million mesh. 
As the flow in the ventilation duct and the cabin is turbulent, Realizable k- $\varepsilon$ turbulence model was utilized. A half of the tramcar was numerically modelled due to the longitudinal symmetry. The computations were performed with nearly 20 million computational elements (Fig. 2b). The mesh independency of the results was assured by the selection of different mesh qualities. Fig. 3a, 3b and 3c depict the velocity fields obtained with 10, 20 and 30 million meshes, respectively. The flow field obtained with 20 and 40 million mesh elements demonstrate a similar signature. With this mesh structure, a typical numerical simulation takes nearly 65 hours on a Dell W2145 (Xeon $3.7 \mathrm{GHz}, 128 \mathrm{~GB}$ ) work station.

\section{Results}

\subsection{Pre-Cooling Mode}

Before the start of the tramcar's operation, the HVAC system must bring the temperature in the cabin to the desired level in a reasonable time. There is no passenger in the tram for these simulations. In the case of cooling, the outside temperature is considered as $40^{\circ} \mathrm{C}$ in extreme summer conditions. The ventilation system reduces the cabin temperature from $40^{\circ} \mathrm{C}$ to $31^{\circ} \mathrm{C}$ in nearly 18 seconds as shown in Fig. 4a. This value is satisfactory for pre-cooling period.
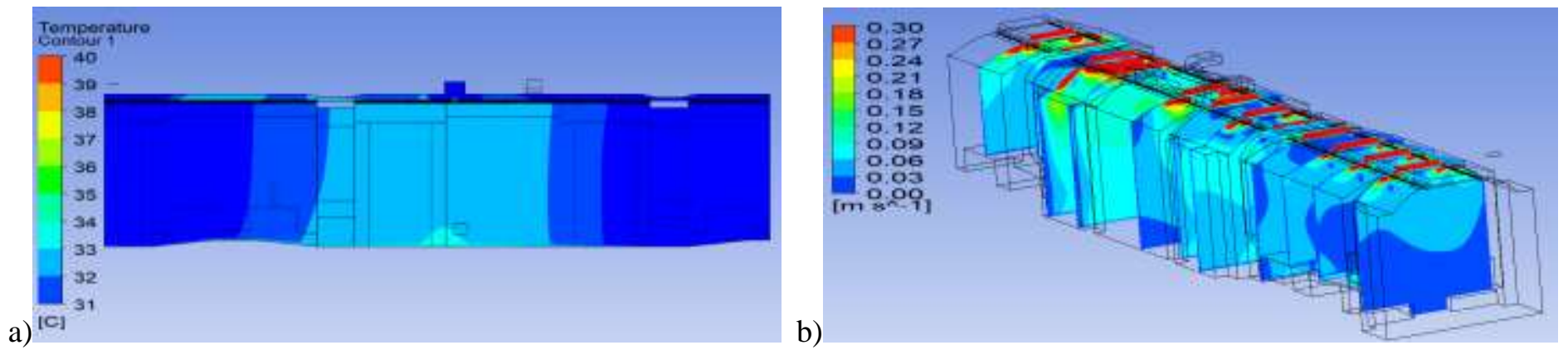

Fig. 4: Cooling mode: a) temperature distribution (the side view), b) the velocity distribution (isometric view).

The velocity distribution obtained in the cooling mode is presented in Fig. 4b. The velocity values do not exceed 0.3 $\mathrm{m} / \mathrm{s}$ and the comfort conditions specified in the standard is achieved. The computed velocity values serve as the initial condition of the simulations for the tramcar under operation.

\subsection{Pre-Heating Mode}

In the heating mode under extreme winter conditions, the outside temperature is considered as $-40^{\circ} \mathrm{C}$. The ventilation system increases the cabin temperature from $-40^{\circ} \mathrm{C}$ to $10^{\circ} \mathrm{C}$ in nearly 300 seconds. Fig. 5a illustrates the temperature contours. The velocity field (the isometric view) is depicted in Fig. 5b. In this mode the velocity values also so not exceed $0.3 \mathrm{~m} / \mathrm{s}$ maximum allowed value. The pre-heating/pre-cooling times are within reasonable limits ( $3-5$ minutes). The maximum preconditioning period is observed in the pre-heating case in which the outdoor temperature is $-40^{\circ} \mathrm{C}$.
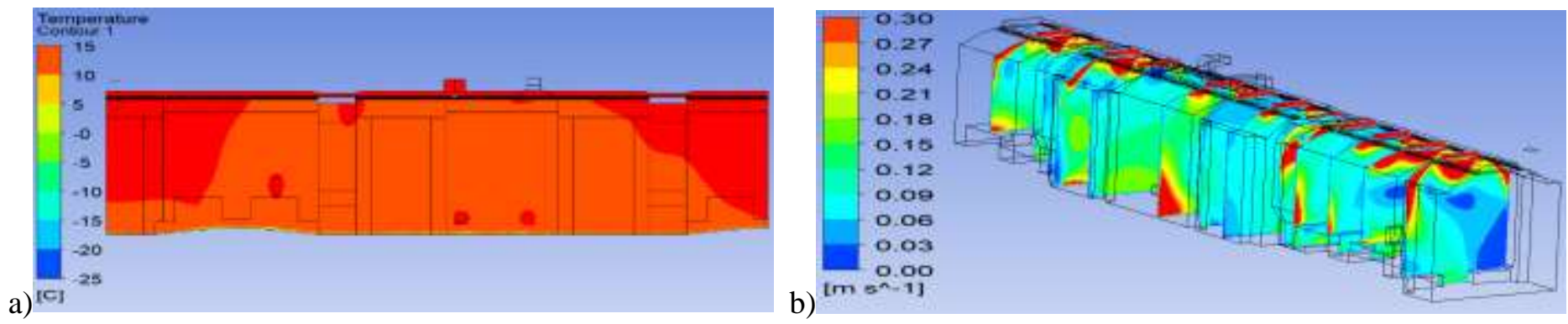

Fig. 5: Heating mode: a) temperature distribution (the side view), b) the velocity distribution (isometric view).

\subsection{Cabin with Passengers}

After the preheating/precooling operations are completed, the simulation is carried out for the cabin with passenger for the tramcar under operation for 2 minutes. The velocity distribution in the cabin at $t=120 \mathrm{~s}$ is presented in Fig. 6a. The velocity is below the $0.3 \mathrm{~m} / \mathrm{s}$ at the head level in almost entire cabin. 


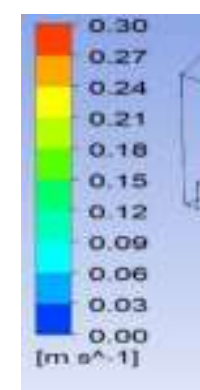

a)

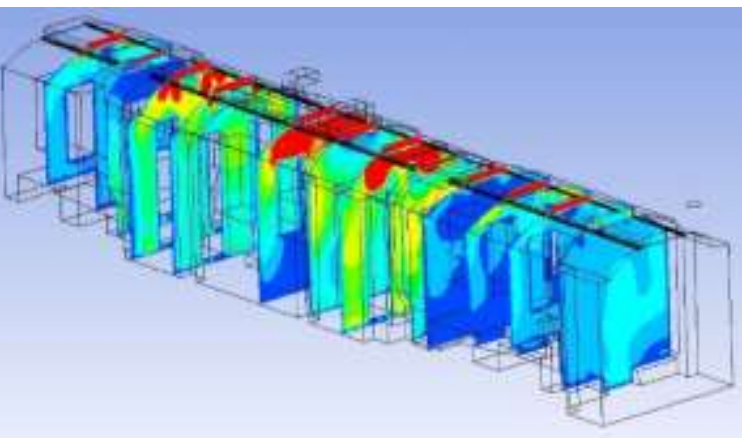

Fig. 6: a) Velocity, b) Temperature distributions in the cabin with passengers

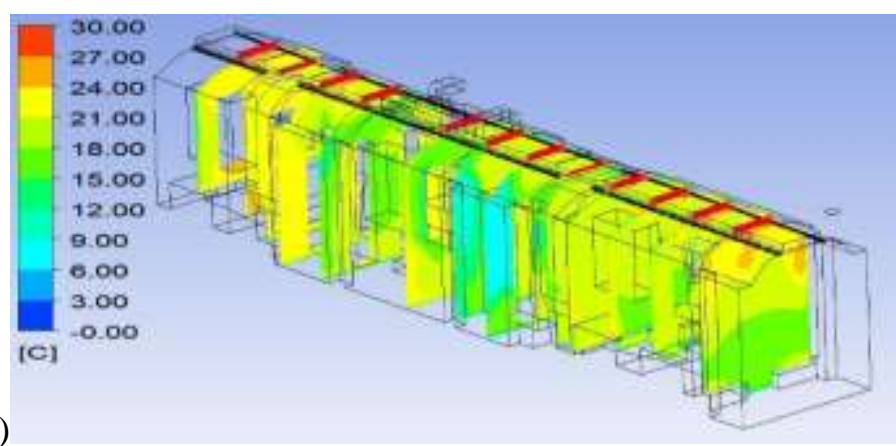

b)

The desired temperature distribution was also achieved by 40 seconds as depicted in Fig. $6 \mathrm{~b}$.

\section{Conclusion}

The three dimensional and transient flow and temperature fields in a tramcar cabin were computed. The simulation were performed on ANSYS Fluent platform. The duration for both pre-cooling and pre-heating of the cabin were calculated for summer and winter temperature conditions and found to be less than 5 minutes for all operating conditions. The flow field in the cabin with passengers was also studied. The obtained results demonstrated that air velocity in the cabin at the head level of the standing and seated passengers do not exceed the upper limit accordance to the EN 147501 standard. With the present ventilation duct and vent design the thermal comfort conditions in the cabin are satisfied.

\section{Acknowledgements}

The authors gratefully acknowledge the financial support for this work received from Bozankaya Corporation and The Scientific and Technological Research Council of Turkey (TUBITAK) under Grant \# 5160086.

\section{References}

[1] V. Bianco, O. Manca, S. Nardini, M. Roma, "Numerical investigation of transient thermal and fluidynamic fields in an executive aircraft cabin," Appl. Therm. Eng., vol. 29, no. 16, pp. 3418-3425, 2009.

[2] S. Zhu, P. Demokritou, J. Spengler, "Experimental and numerical investigation of micro-environmental conditions in public transportation buses," Build. Environ., vol. 45, no. 10, pp. 2077-2088, 2010.

[3] W. Liu, S. Mazumdar, Z. Zhang, S. B. Poussou, J. Liu, C.-H. Lin, Q. Chen, "State-of-the-art methods for studying air distributions in commercial airliner cabins," Building Environ., vol. 47, pp. 5-12, 2012.

[4] R. de Lieto Vollaro, "Indoor climate analysis for urban mobility buses: A CFD model for the evaluation of thermal comfort," Int. J. Environ. Prot. Policy, vol. 1, pp. 1-8, 2013.

[5] C. Suárez, A. Iranzo, J. A. Salva, E. Tapia, G. Barea, J. Guerra, "Parametric investigation using computational fluid dynamics of the HVAC air distribution in a railway vehicle for representative weather and operating conditions," Energies, vol. 10, pp. 1074-1-13, 2017.

[6] A. Iranzo, J. A. Salva, J. Guerra, G. Barea, F. J. Pino, "Air ventilation and comfort in railway vehicles operating in ventilation mode," J. Thermal Sci. Eng. Appl., vol. 11, pp. 031010-1-9, 2019. 